Vol. 18 (2009): 3-15.

\title{
Third sector organizations in rural development: a transaction cost perspective
}

\author{
Vladislav Valentinov \\ Leibniz Institute of Agricultural Development in Central and Eastern Europe, Theodor-Lieser-Str.2, 06120, Halle, \\ Germany,email: valentinov@iamo.de
}

\begin{abstract}
In many parts of the world, rural development is supported by third sector organizations, such as nongovernmental organizations, farmer associations, and cooperatives. This essay develops a transaction cost explanation of these organizations' role in rural areas. Since the traditional transaction cost theory is concerned with the choice of governance mechanisms within the for-profit sector, this essay adopts an alternative conceptualization of the notion of transaction cost by building on the theory of the division of labor. This theory regards transaction cost as a constraint on the division of labor causing the replacement of exchange with self-sufficiency. The proposed transaction cost explanation of rural third sector organizations consists of two arguments: 1) third sector organizations embody partial reliance on self-sufficiency; and 2) rural areas exhibit rurality-specific transaction cost acting as a constraint on the division of labor and thus creating a niche for third sector organizations. The essay concludes with suggesting a research program on developing an economic theory of the rural third sector.
\end{abstract}

Key-words: rural development, transaction costs, third sector organizations, self-sufficiency.

\section{Introduction}

In many countries of the world, the development of rural areas is actively supported by third sector organizations (TSOs), i.e., organizations representing neither for-profit firms nor governmental agencies (OECD 2006, Uphoff 1993). Defined as private, nonprofit-distributing, democratically self-governed, and voluntary entities (Salamon et al. 2003), TSOs affect the development of rural areas and agrifood chains in a variety of ways, e.g. by enhancing farmers' market power (Hueth and Marcoul 2003), articulating the political interests of rural populations (OECD 2006), promoting the development of rural diversification (Renting et al. 2003, van der Ploeg et al. 2000), as well as by other case-specific means of improving the well-being of rural dwellers (Uphoff 1993). Yet, 


\section{AGRICULTURAL AND FOOD SCIENCE}

Valentinov, $V$. Third sector organizations in rural development

despite the substantial progress in the development of the general economic theory of TSOs (see e.g. Steinberg 2006 for an overview), rurality has so far not been hypothesized to be a possible determinant of TSOs' existence. This essay is aimed at elaborating this hypothesis by building on the transaction cost theory and combining it with the theory of the third sector.

The motivation to apply the transaction cost theory to explain the existence of rural TSOs rests on the widely acknowledged usefulness of this theory in explaining the choice among governance mechanisms. The transaction cost theory demonstrates that governance mechanisms differ in their ability to economize on transaction cost in different transactional situations, and it is these differences that explain why some governance mechanisms are sometimes preferred over others. Given that some rural TSOs (such as cooperatives) have been considered to be governance mechanisms comparable with markets and hierarchies (Menard 2004, Bonus 1986, Staatz 1987), it stands to reason that the existence of such TSOs may be explicable in terms of their relative advantages in economizing on transaction cost in specific transactional situations. This heuristic strategy has, in fact, been pursued in a number of studies viewing cooperatives as hybrids between market and hierarchy (most importantly, Menard 2004, Bonus 1986).

This essay will, however, contend that this view of cooperatives, while not without a certain merit, is questionable on its own grounds and cannot be generalized to the whole third sector. It will be argued that the conceptual relationship between TSOs, on the one hand, and markets and hierarchies, on the other, is not adequately captured by variations of their transaction cost-economizing capacities along a continuum of transactional characteristics (such as e.g. asset specificity). Instead, the essay will develop an alternative transaction cost explanation of the existence of TSOs that takes due account of the differences in the economic roles of TSOs and for-profit firms, as emphasized in the theories of the third sector (Steinberg 2006, Hansmann 1987). Importantly, this explanation will be shown to be related to the rural areas' characteristics that lie at the heart of the rural development challenges throughout the world. The essay concludes with discussing implications of the proposed transaction cost explanation of TSOs for the major economic theories of the third sector as well as for the further research on rural development.

\section{The logic of institutional response to transaction cost}

\author{
The continuum of governance \\ mechanisms: the place of TSOs
}

In his seminal 1937 article on the nature of the firm, Ronald Coase emphasized that using the price mechanism has a cost, primarily consisting of the cost of discovering the relevant prices. This cost, in his view, explained why some resources are more efficiently allocated within (for-profit) firms rather than through market exchange relationships between these firms. Subsequent literature extended the Coasean insights to take account of incentive alignment as the problem of safeguarding against opportunistic and strategic behavior (Alchian and Demsetz 1972, Williamson 1985). In the 1990s, this literature experienced a further shift from the classic dichotomy between market and hierarchy to an interest in the broad range of institutional arrangements designated as hybrids (Menard 2004). The significant diversity of hybrid institutional arrangements raised the issue of governance mechanisms' classification, which has been realized in various versions of the 'governance continuum' delimited by the polar modes of market and hierarchical organization (e.g., Williamson 1991, Mahoney 1992, Peterson et al. 2001). Originally conceived by Williamson (1991), governance continuums involved a specification of criteria with respect to which various governance mechanisms are structured into a logical sequence. For instance, Williamson (1991) differentiated the transaction cost-economizing ability of various governance mechanisms according to their incentive intensity, reliance on administrative controls, 
the type of economic adaptation they support, and the type of contract law they use.

Thus, viewing TSOs as hybrids between market and hierarchy requires specifying classification criteria according to which TSOs could be clearly assigned an intermediate position between these polar modes of economic organization. Interestingly, studies advocating the hybrid nature of (some of) TSOs were not explicit about these criteria (e.g. Menard 2004, Bonus 1986). Strictly speaking, until these criteria are identified, there are no grounds for assuming the hybrid nature of TSOs. However, there is an even more important reason why the designation of TSOs as hybrids must be called into question, and this reason follows from the very definition of the third sector.

Specifically, the third sector is defined as such in contrast to the private for-profit sector and the governmental sector, and is justified in terms of the latter sectors' failures (Steinberg 2006, Ott 2001, Hansmann 1987). At the same time it is evident that the continuum of governance mechanisms ranging from market to hierarchy is descriptive of the forprofit, rather than of the third, sector. Indeed, if any particular transactions can be satisfactorily organized through spot market, or vertical integration within for-profit firms, or any forms of intermediate (relational or long-term) contracting in the market, these transactions do not need to be undertaken by the third sector. Moreover, the substantial literature designated as 'the theory of the firm' is clearly concerned with for-profit firms rather than with TSOs fundamentally differing from for-profit firms in being non-profit-distributing and democratically self-governed ${ }^{1}$. Thus, defining TSOs as entities

$1 \quad$ Oliver Williamson (e.g. 2002, 1996, 1985) repeatedly emphasized that the transaction cost-economizing logic is useful in explaining the existence of hybrid and nonstandard forms of contracting, of which TSOs may be assumed to be one example. This assumption however must countered with the fact that these forms of contracting are always entertained by for-profit firms. Since TSOs are defined and justified in terms of the tasks that cannot be delegated to for-profit firms, TSOs cannot be regarded in the same way as e.g. 'customer and territorial restrictions, tie-ins, block booking, franchising, vertical integration, and the like' (Williamson 1985, p. 19). performing tasks that can be performed neither by markets, nor by for-profit firms, nor by any forms of intermediate contracting involving these firms, necessarily entails rejecting the representation of TSOs as hybrids between market and hierarchy. The TSOs' exclusion from the governance continuum poses, however, several new issues. First, if the traditional transaction cost-economizing framework is unsuitable for conceptualizing the relationship of TSOs to the elements of the governance continuum, what alternative framework must be used? Is the concept of transaction cost still relevant to it? Second, since this essay is particularly concerned with rural TSOs, it will be necessary to examine the relationship between rurality and the rationale for TSOs in the alternative framework to be proposed. These issues are addressed in the following subsections.

\section{Toward an alternative transac- tion cost view of TSOs}

As shown above, the traditional transaction cost theory explains the existence of various governance mechanisms within the for-profit sector, but does not extend beyond this sector's boundaries. It could be concluded at this point that the concept of transaction cost does not present an appropriate theoretical tool for explaining the existence of the third sector. This conclusion would be warranted if the significance of transaction cost for the operation of a market economy were limited to causing the emergence of transaction cost-economizing governance mechanisms. This limitation, however, is not the case (see Valentinov 2008). Transaction cost not only explains the existence of specific governance mechanisms within a market economy, but circumscribes the extent of the market economy itself. This is a point which falls beyond the scope of the traditional transaction cost theory but is emphasized by the theory of the division of labor dating back to Adam Smith. This theory consists of two principal propositions. One is that the division 


\section{AGRICULTURAL AND FOOD SCIENCE}

Valentinov, $V$. Third sector organizations in rural development

of labor improves productivity due to the existence of gains from specialization; the other is that the division of labor is limited by a number of factors, such as the extent of the market (Smith 1981), transaction cost (Becker and Murphy 1992, Yang and Borland 1991), and availability of knowledge (Becker and Murphy 1992).

Thus the theory of the division of labor locates the role of transaction cost in drawing the boundary between those human wants (preferences) that can be gratified by relying on the division of labor, and those that cannot. Crucially, this theory does not claim that the latter wants must remain ungratified; rather, it sees the mechanism of their gratification not in the division of labor and exchange, but in self-sufficiency which is understood as production for one's own consumption (e.g. Demsetz 1997, p. 7). This theory thus suggests that there exist two basic and complementary mechanisms of gratification of human wants, exchange and selfsufficiency, whose range of application depends on the size of transaction cost. The higher this cost, the more wants must be gratified through selfsufficiency; the lower this cost, the greater space is available for relying on the division of labor and exchange. Gratification of wants through the division of labor and exchange is superior in the sense that it is supported by the existence of gains from specialization. Yet, when the generation of these gains is precluded by high transaction cost, individuals nevertheless seek to gratify their wants through self-sufficiency, despite the higher cost of doing so.

Hence, from the perspective of the theory of the division of labor, transaction cost gives rise to two types of institutional response. First, to the extent that transaction cost can be reduced, it causes the emergence of institutions facilitating market exchange, most importantly the institution of the for-profit firm. Second, to the extent that transaction cost acts as a constraint on the division of labor, it causes the emergence of institutions of self-sufficiency. Importantly, the occurrence of positive transaction cost in its latter capacity does not mean that human wants remain ungratified; rather it means that these wants can be gratified through self-sufficiency and not through exchange, i.e. without realizing the gains from specialization.

While the first type of institutional response has been widely discussed in the institutional economics literature, the second response has been practically never mentioned (with the important exception of Demsetz (1997)). It is therefore necessary to be clear about what institutions may represent self-sufficiency. A major fact about self-sufficiency is that it may be individual or collective (since not only individuals, but also groups can produce for purposes of own consumption). Individual self-sufficiency is embodied in individual autarky, while collective self-sufficiency is represented by a range of mutual self-help organizations producing goods and services for consumption by their members. Individual autarky, in the form of e.g. subsistence farming, is a common occurrence in many rural areas across the world, but it presents a relatively weak mechanism for supporting rural development, as compared with collective self-sufficiency. Importantly, in order to be designated as embodying self-sufficiency, mutual self-help organizations need not fully provide their members with the means of living. Rather, any instance of production of outputs for purposes of own consumption makes these organizations selfsufficient with respect to these particular outputs. Clearly, this understanding of self-sufficiency does not imply that these organizations are generally prohibited from buying and selling in the marketplace; rather, it simply requires these organizations to produce at least some outputs for purposes of own consumption by members.

Given the existence of exchange and selfsufficiency as the alternative and complementary mechanisms of gratifying human wants, TSOs must be recognized as exhibiting an important affinity with the latter mechanism, and more specifically, as embodying partial collective selfsufficiency. The self-sufficiency nature of TSOs can be seen in the fact that their organizational goals are constituted by missions rather than by monetary gain. Indeed, monetary gain as a motivation for business activity is a distinctive feature of the for-profit sector and underlies the operation of all above-mentioned governance mechanisms, 
Vol. 18 (2009): 3-15.

including market, hierarchy, and any intermediate contracting forms. By contrast, self-sufficiency as production for one's own consumption must be guided by the utility from consuming this production's outputs. Evidently, the same motivation is characteristic of TSOs because the pursuit of TSOs' missions must enhance the utility of at least some of these organizations' stakeholders. Deriving utility from contributing to the realization of TSOs' missions, these stakeholders do not need monetary remuneration as a motivation for doing so. Hence, since the pursuit of mission is the source of utility to these stakeholders, their involvement in TSOs represents the gratification of their wants through self-sufficiency. In line with the theory of the division of labor, these stakeholders resort to self-sufficiency because the gratification of their wants through the system of division of labor, embodied in the for-profit sector, is prevented by high transaction cost. Importantly, this argumentation does not require all TSOs' stakeholders to derive utility from contributing to the realization of TSOs' missions. For the designation of the third sector as an embodiment of self-sufficiency to be valid, it is sufficient that at least some of these stakeholders do so.

\section{Explaining rural TSOs}

If TSOs are generally explained as an embodiment of self-sufficiency arising from the transaction costrelated (as well as other) constraints on the system of the division of labor, how does this view inform the analysis of rural TSOs? The applicability of the proposed transaction cost framework to explaining the existence of rural TSOs is grounded on the fact that rural areas, in both developed and developing countries, have a number of socio-economic characteristics that result in high transaction cost hindering the development of the system of the division of labor. These characteristics of rural areas most importantly include relatively low population density, significant geographic dispersion of consumers and producers, and relatively poor infrastructure
(Terluin 2001). These characteristics thus imply that transaction cost standing in the way of interaction between consumers and producers is higher in rural areas than urban ones. In the following, transaction cost stemming from these characteristics will be referred to as 'rurality-specific'.

The argument about the effect of rurality on transaction cost of exchange must be seen in the context of two qualifications. First, rural development scholars often emphasize that there is no universally accepted definition of rurality (e.g., Baum and Weingarten 2004). Terluin (2001) distinguishes between definitions used by the OECD, by the European Commission, and by policymakers in various EU member states. Variations in approaches to defining rurality suggest that it may be conceptualized in terms of a continuum of characteristics, each of which gives rise to the rurality-specific transaction cost. The more these characteristics are pronounced in particular rural areas, the higher will be the rurality-specific transaction cost, and the greater will be the difference between transaction cost levels in the respective rural and urban areas. Operationalizing this argument for the purposes of empirical research will thus require a specification of the approach taken to define rurality. The second qualification is that transaction cost levels in rural areas depend not only on the above-mentioned characteristics of these areas, but also on the state of formal and informal institutional environment, e.g. the presence of trust and social relationships (e.g., Woolcock and Narayan 2000). In the proposed argument, the latter determinants of transaction cost are subsumed in the ceteris paribus conditions. Operationalizing the argument will require making these determinants explicit.

Transaction cost analyzed by the traditional transaction cost theory can be meaningfully thought of as being reduced (economized) by using the right governance mechanisms. In contrast, the above mentioned characteristics of rural areas represent 'brute facts' that cannot be altered by using any governance mechanism; hence, the rurality-specific transaction cost does not meaningfully yield itself to being economized. Evidently, the inability of the rurality-specific transaction cost 


\section{AGRICULTURAL AND FOOD SCIENCE}

Valentinov, $V$. Third sector organizations in rural development

of being economized explains the persistence of the rural development challenges throughout the world. Indeed, transaction cost obviously exists in urban regions as well, but there it can be relatively well economized by for-profit governance mechanisms, ranging from market through intermediate contracting to hierarchy. It is precisely the relative absence of these governance mechanisms in rural areas that gives expression to the numerous rurality-specific problems that are supposed to be alleviated by the rural development policies. That for-profit governance mechanisms do not arise to economize on the rurality-specific transaction cost suggests that this cost is more appropriately conceived of as a constraint on the division of labor, rather than as a factor of institutional choice among for-profit governance mechanisms, as suggested by the traditional transaction cost theory.

To the extent that transaction cost acts as a constraint on the division of labor, it gives rise to the superseding of exchange by self-sufficiency, which may take individual and collective institutional forms. The choice among these forms is primarily determined by production cost considerations, implying that the institutional form of collective self-sufficiency is chosen by rural dwellers for governing those activities in which it yields a production cost advantage compared to individual self-sufficiency. Examples of activities that are typically undertaken by rural TSOs on the self-sufficiency basis include maintenance of local culture and infrastructure, provision of social services (e.g. Uphoff 1993), administering the use of common pool resources (e.g. Poteete and Ostrom 2008), or, in the case of some agricultural cooperatives, organization of product marketing and of input supply as well as delivery of technological services (Staatz 1987). These activities either cannot be organized by the for-profit sector, or, in the case of some agricultural cooperatives, their delegation to the for-profit sector may result in higher costs to agricultural producers. The variety of activities performed by rural TSOs is reflected in the variety of TSOs' structural types, such as agricultural and rural cooperatives, rural partnerships, community organizations, associations, nongovernmental organizations (NGOs), informal self-help groups, etc. Again, it bears repeating that the TSOs' self-sufficiency nature means that their core outputs are produced for own consumption of their members. Crucially, this condition does not prevent TSOs from producing a portion of their outputs for sale in the market.

The proposed transaction cost explanation of rural TSOs is evidently subject to the major qualification that not all transaction cost occurring in rural areas needs to act as a constraint on the division of labor rather than as a factor of institutional choice among for-profit governance mechanisms, as assumed by the traditional transaction cost theory. Rural areas, just like urban ones, are marked by the existence of the two distinct types of transaction cost acting in these two roles. Therefore, to the extent that transaction cost acts as a constraint on the division of labor, it gives rise to TSOs as embodiments of self-sufficiency; to the extent that it acts as a factor of institutional choice among for-profit governance mechanisms, it may underlie the occurrence of any one of these, including market, intermediate contracting, and hierarchy. This distinction evidently applies to both rural and urban areas. Explaining TSOs as a consequence of the transaction cost-induced self-sufficiency thus contradicts neither the existence of the for-profit sector in rural areas nor the existence of the third sector in urban areas, in which the extent of the division of labor is necessarily limited as well.

Differentiating between the two distinct types of transaction cost invites the question of these types' relationship to each other. Central to answering this question is Williamson's (1996, p. 12) argument that the transaction cost economized by governance mechanisms stems from contractual hazards which, in turn, can be attributed to the behavioral assumptions of bounded rationality and opportunism. Crucially, the notion of contractual hazards implies the (pre-)existence of contractual parties. Indeed, unless these parties exist, they cannot perceive contractual hazards and devise hazard-mitigating (i.e., transaction cost-economizing) governance mechanisms. In contrast, the transaction cost acting as a constraint on the division of labor determines the extent to which the potential contractual parties come into existence in the first 
Vol. 18 (2009): 3-15.

place. Evidently, if transaction cost acting as a constraint on the division of labor is prohibitively high, there can be only few contractual relationships and thus few contractual hazards to be mitigated. Hence, the transaction cost effect of rural areas' characteristics such as sparse population, geographical dispersion, and poor infrastructure, is appropriately seen not in increasing contractual hazards but in reducing the number of economic units that might consider entering any contractual relationships at all. Again, to the extent that there exist some potential contractual parties, they may consider the relevant contractual hazards and devise the transaction cost-minimizing governance mechanisms belonging to the for-profit sector.

\section{Some stylized evidence}

The above transaction cost explanation of rural TSOs is a hypothetical framework intended for guiding further empirical research. While the empirical testing of this framework is beyond the scope of the present paper, it is possible to cite a few stylized facts lending indirect support to the proposed argument. One strand of stylized evidence refers to the rural disadvantage, understood as ruralityspecific set of difficulties preventing people from participating fully in society, including poverty, lack of skills, and low levels of health (Commission of Rural Communities 2006). A recent study by the Commission of Rural Communities in the United Kingdom found evidence of several types of the rural disadvantage in this country: disadvantage in personal finance, employment, education, housing, health, access to retail infrastructure, transport, and civic participation. The rurality-specific deterioration in the quality of rural life has been identified also in the United States, particularly in the work coordinated by W.K. Kellogg Foundation. Various writers have argued that in the United States, rurality is often associated with the lack of affordable and adequate child care (Pindus 2001), weaker economic development, lower per-capita incomes, limited employment and education opportunities (Weber et al. 2002). The rural disadvantage often dictates the need in the enhanced provision of social services which is a classic activity type of TSOs (Kendall et al. 2006).

Another strand of stylized evidence is based on the empirical research by the National Council of Voluntary Organizations and by the Countryside Agency in the UK. Conducted in 2001, this research encompassed collecting data on the scope and activities of TSOs in two UK rural districts, Teesdale and East Northamptonshire (Yates 2002). It has been, in particular, found that the TSOs' activity levels in rural areas are considerable above the average national level. Indeed, 5.6 TSOs per one thousand people have been identified in East Northamptonshire, and 10.8 TSOs per one thousand people in Teesdale, whereas a comparable research by the UK Home Office in 1994-5 found an average rate of 2.6 TSOs per one thousand people in urban areas. Moreover, rural dwellers have been found to be significantly more likely to donate time and effort to TSOs than people living in urban areas. In East Northamptonshire, TSOs benefited from the unpaid work of over 8,451 individuals, which is equivalent to 113 unpaid workers per one thousand people; in Teesdale, TSOs benefited from the work of approximately 4,963 volunteers, which is equivalent to 198 unpaid workers per one thousand people (ibid). These figures clearly contrast with the UK national average volunteering rate of 22 to 75 volunteers per one thousand people (ibid).

To be sure, these stylized facts per se do not constitute a proof of the effect of the rurality-specific transaction cost on the emergence of rural TSOs. However, they suggest that the rationale for the emergence of TSOs may be more strongly characteristic of rural areas than urban ones, and this is consistent with the proposed argument. While the rural disadvantage means greater space for mutual self-help initiatives, the data on higher volunteering rate in rural areas suggest that these initiatives are indeed being taken. Much more research is however necessary to clarify the complex causal linkages between the rurality-specific transaction cost, rural disadvantage, and the demand for and supply of rural TSOs. 


\section{Implications for the economic theories of the third sector}

\section{Self-sufficiency and mission orientation}

As mentioned above, self-sufficiency denotes production aimed at the satisfaction of consumption preferences of those who exercise the production. The notion of self-sufficiency is therefore very close to James' (1983) characterization of TSOs as 'consumption-oriented institutions', whose 'consumption-oriented' nature reveals itself in their mission orientation (Minkoff and Powell 2006). Economists traditionally represent the mission orientation of TSOs in terms of nonpecuniary preferences of their managers which may seek, among other things, maximization of TSOs' output quantity and quality, maximization of the use of preferred inputs, and realization of ideology (see e.g. Steinberg 2006, Lakdawalla and Philipson 2006). Since these nonpecuniary preferences are the key motivators of the TSOs' operation, there are appear to be no formal obstacles in designating TSOs as self-sufficient with respect to these preferences, or more generally, with respect to their missions. Crucially, the proposed notion of TSOs' self-sufficiency does not mean that they are autarkic and do not enter purchase and sale transactions in the market. Rather, this notion involves a major qualification to the effect that TSOs are deemed as self-sufficient only with respect to their core missions, but not with respect to their whole range of activities, which may include commercial operations aimed at cross-subsidizing the mission-related activities. Hence, to say that TSOs are self-sufficient with respect to their missions is to say no more than that these missions represent the key nonpecuniary motivation of TSOs' decision-makers.

Given this qualification, what is the added value of the proposed terminological use of the notion of self-sufficiency? Apart from demonstrating the basic congruence of this notion in the rural context with the fact of the mission orientation of TSOs in general, designating TSOs as self-sufficient has an additional theoretical implication. Specifically, since self-sufficiency means productive activity directly driven by the desire to satisfy certain consumption preferences of those exercising this activity, this notion implies that these consumption preferences have motivated the initiation of the activity in question.

To appreciate the significance of this implication, consider the fact that many neoclassical behavioral models of TSOs have been built on the assumption that third sector managers pursue nonpecuniary preferences because they are prevented from pursuing the profit maximization objective by the nondistribution constraint (Lakdawalla and Philipson 2006, James and Rose-Ackerman 1986). In contrast to this assumption, the self-sufficiency notion presupposes a reverse causation: third sector managers do not maximize profit because they are intrinsically interested not in profit but in the gratification of their nonpecuniary consumption preferences. The nondistribution constraint serves merely as a legal expression of this fact. In this context, the role of the specific economic theories of the third sector is to explain why specific nonpecuniary consumption preferences cannot be gratified through the operation of for-profit firms and thus require recourse to self-sufficiency. A reconstruction of the major theories along these lines is outlined in the following subsection.

\section{Revisiting the major economic theories}

This section will argue that the major economic theories of the third sector are consistent with its designation as embodying self-sufficiency rather than exchange. Moreover, these theories will be shown to reveal specific reasons why certain kinds of transaction cost cannot be significantly reduced by for-profit organizational arrangements. The section will be structured according to the major theories of the third sector, such as the public goods theory, consumer control theory, trustworthiness theory, and supply-side theory. 
Vol. 18 (2009): 3-15.

The public goods theory of TSOs, developed by Weisbrod (1988), argues that the government provides public goods to meet the needs of the median voter. If a fragment of the population happens to have a greater need for a certain public good than is the case with the median voter, or needs a particular variety of this good that is different from the standard variety, then TSOs represent a mechanism for satisfying this residual demand by means of privately producing these public goods by those who need them. More importantly for the present discussion, this governmental failure also represents market failure, because for-profit firms are prevented from supplying the required public goods due to the free-rider problem. It is evident that private production of public goods by those who need these goods for consumption purpose represents the process of self-sufficiency, since the founders of respective firms produce these public goods for own consumption rather than for sale.

A related type of market failure that TSOs can theoretically correct is emphasized by the 'consumer control' theory, which argues that markets may not ensure sufficiently strong consumer control over the activities of firms (Ben-Ner 1986). Stricter consumer control may be necessary to resist opportunistic behavior by managers and to guarantee that products offered by firms are of a sufficiently high quality (ibid). TSOs emerge by means of consumers taking over control of these firms, thus transforming them into a variety of consumer cooperatives. This transformation clearly indicates a partial substitution of the reliance on market exchange by the reliance on self-sufficiency. Indeed, instead of delegating the organization of respective production activities to for-profit firms, consumers need to organize them themselves. By organizing them on their own, they signal that they do not see an opportunity for gratifying their consumption preferences through market exchange institutions.

According to the trustworthiness theory of TSOs, TSOs reduce firm managers' opportunistic behavior by imposing on them the nondistribution constraint, whose role lies in dampening their incentives to exploit the limited ability of consumers to evaluate the quality of products and services produced (Hansmann 1987). The nondistribution constraint aligns the incentives of consumers and producers in such a way that incentives for opportunism are weakened. In fact, this explanation of the market failure-addressing role of TSOs is not different from the respective explanation of the way for-profit firms align incentives in situations involving information asymmetry. Thus, in the trustworthiness theory framework, TSOs appear to address market failure in the same way for-profit firms do, i.e., without recourse to self-sufficiency. This conclusion, however, must be examined in the light of the fact that the trustworthiness theory itself is incomplete because it does not clarify the nature of entrepreneurial motivation guiding the adoption of the nondistribution constraint. Specifically, the prospect of making a profit represents a source of motivation for an entrepreneur to undertake a particular activity. This motivation is lost if profit can no longer be appropriated and the nondistribution constraint is perfectly enforced. Indeed, if an entrepreneur receives zero profit, why does she not switch to another area of business, where her profit could be greater than zero?

Hence, the ability of TSOs to utilize the nondistribution constraint as an incentive alignment device depends on the presence of a certain nonmonetary motivation, which must substitute for the lost motivational role of profit appropriation (e.g., Young 1983). Nonmonetary motivation explains why those stakeholders who derive zero profits from the operation of their TSOs nevertheless remain willing to keep these organizations in operation. Economists have devised a number of conceptualizations of such nonmonetary motivation, including utility from practicing commitment, sympathy, reciprocity, or receiving private benefits such as prestige and pride (see e.g. RoseAckerman 1996, p. 714). However, each case of obtaining utility from involvement in particular activities represents self-sufficiency, for the reason that these activities are not delegated to specialized suppliers through the system of market exchange. Hence, from a logical point of view, practicing commitment, sympathy or reciprocity represents self-sufficiency in much the same way as producing public or private goods for the purpose of own consumption. 


\section{AGRICULTURAL AND FOOD SCIENCE}

Valentinov, $V$. Third sector organizations in rural development

The objective of the supply-side theory of the third sector is to understand the motivation of entrepreneurs who choose to found TSOs rather than for-profit firms (e.g. Rose-Ackerman 1996, Young 1983). Of all economic theories of the third sector discussed in this paper, this theory is the one whose consistency with the self-sufficiency view of this sector is most straightforward. A central concept in the supply-side theory is that of ideological entrepreneurship, implying that TSOs are created by those entrepreneurs who seek not to generate profit, but rather to practice or disseminate particular ideologies and beliefs. Nonpecuniary preferences for practicing these ideologies and beliefs thus represent the object of self-sufficiency of the respective TSOs.

\section{Implications for rural develop- ment research}

In the rural development literature, TSOs are recognized for their important contribution to the development of rural areas (OECD 2006, Uphoff 1993). In the developed countries, the role of the rural third sector has been recently enhanced by the shift 'from government to governance' involving the increasing transfer of responsibilities from the state to the private for-profit and third sectors (Goodwin 1998). In the developing countries, the contribution of the rural third sector has been appreciated primarily as a result of relatively low effectiveness of both state-led and market-led policies of agricultural and rural development (Kydd and Dorward 2004). Yet, in spite of their generally recognized importance, the theoretical understanding of the economic rationale of rural TSOs has remained unsatisfactory. Indeed, as the preceding section has shown, the major economic theories of the third sector have been developed with no regard to the rural context. While all of these theories analyze the way the third sector compensates for the limitations on the ability of for-profit firms to satisfy human needs, they do not ask whether any such limitations could be caused by rurality of regions in which for-profit firms are located. As a result, neither theory is more suitable to explaining the rural third sector than the urban one.

At the same time, as mentioned above, it has been long recognized that rural areas exhibit a number of salient characteristics that result in high transaction cost and thus impair the ability of forprofit firms to fully satisfy the needs of rural dwellers (Terluin 2001). Hence, rurality is a distinct determinant of the emergence of TSOs and thus deserves to be integrated into the general theoretical understanding of the third sector. The basis for this integration is laid by the proposed view of the third sector as an embodiment of self-sufficiency; in this respect, this view's significance is twofold. On the one hand, this view explains how the existence of rural TSOs can be causally related to rural areas' characteristics. Specifically, since these characteristics ultimately boil down to high rurality-specific transaction costs, and transaction cost represents a constraint on the division of labor, TSOs as a form of self-sufficiency is a natural consequence of these characteristics. On the other hand, this view clarifies the logical relationship between the ruralityrelated and the other existing explanations of the third sector by indicating that all of these explanations ultimately seek to discover specific reasons for high transaction cost acting as a constraint on the division of labor and thus causing recourse to self-sufficiency in the form of TSOs.

Thus, the set of the economic theories of the third sector has to be supplemented with what may be called 'the rurality theory'. This theory's major hypothesis would be that the rurality-specific transaction cost gives rise to the emergence of rural TSOs. This hypothesis would be subject to numerous potential qualifications and refinements, which may concern e.g. differentiating between individual determinants of the rurality-specific transaction cost, such as low population density, geographic dispersion of consumers and producers, and poor infrastructure. Furthermore, it may be expedient to differentiate between various types of rural areas' institutional environment determining the extent to which rural TSOs can be maintained in operation. Specifically, other things being equal, TSOs may be 
Vol. 18 (2009): 3-15.

hypothesized to be more present in those rural areas where bureaucratic obstacles to their creation and operation are less significant and where informal institutions, such as social capital, are supportive of local cooperation. It is also important to differentiate between different institutional forms of TSOs, such as agricultural and rural cooperatives, rural partnerships, community organizations, associations, NGOs, and informal self-help groups, whose occurrence is evidently caused by different determinants of rurality-specific transaction cost.

The work on developing the rurality theory of the third sector needs not, however, be confined to testing the above hypothesis in its various modifications. An even more comprehensive understanding of the rural third sector can be achieved by addressing explorative questions following from the logical analysis of the relationship between the concepts of the third sector and rurality. Importantly, both of these concepts derive their meaning from the contrast with their respective alternatives (the third sector is contrasted with market and state and rural areas - with urban areas). Hence, a comprehensive analysis of the relationship between these concepts requires identification not only of their direct logical links, but also of the effects of each of these concepts on the way the other concept is related to its relevant alternative, as shown in the Figure 1. The three logical components of the relationship between the concepts of the third sector and rurality suggest three explorative questions that may guide the development of the economic theory of the rural third sector (see Fig. 1).
The first question is concerned with identifying the peculiarities of the intersectoral institutional choice in rural areas; the second - with testing alternative economic theories of the third sector in rural areas (including both the conventional theories and the proposed rurality theory); the third with comparing the structure and behavior of rural und urban TSOs. At present, it is not yet possible to formulate precise hypotheses regarding how these questions may be answered. This paper's argument about the effects of the rurality-specific transaction cost merely serves to expand the set of hypotheses to be tested in dealing with the second question, but it cannot foresee which of these hypotheses is more likely to be correct. Addressing these questions will require both empirical and theoretical research, which will undoubtedly yield many new insights about both the socio-economic role of the third sector and the futures of rural development.

\section{Concluding remarks}

The proposed alternative transaction cost explanation of TSOs has been motivated by the need to take full account of the specific institutional identity of the third sector as different from the forprofit sector. Since the traditional transaction cost theory is concerned with the choice of governance mechanisms within the for-profit sector, explaining the third sector in transaction cost terms calls for

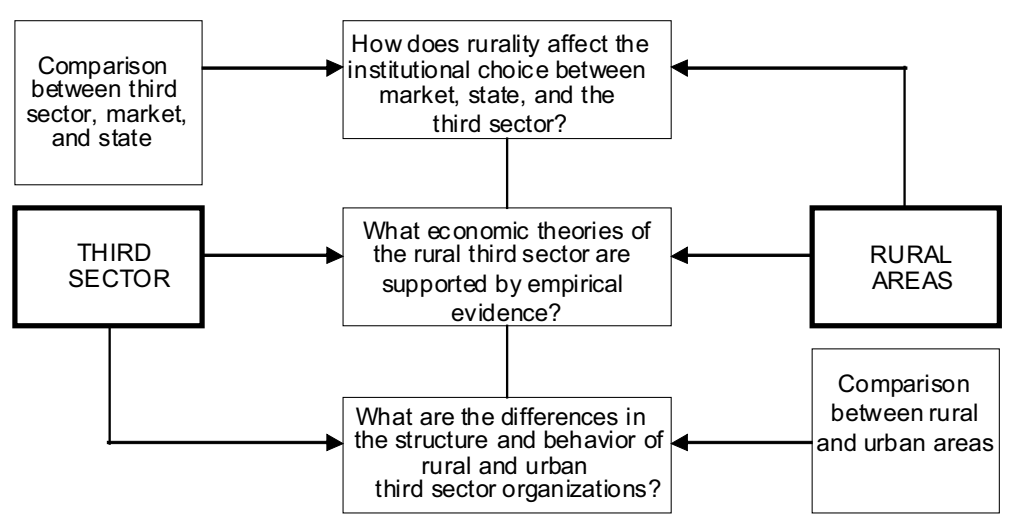

Fig. 1. Explorative questions of the economic theory of the rural third sector 


\section{Valentinov, $V$. Third sector organizations in rural development}

an alternative conceptualization of the notion of transaction cost. This conceptualization is possible in the framework of the theory of the division of labor, regarding transaction cost not as a factor of choice among market, hierarchy, and intermediate contracting, but as a constraint on the division of labor. It its latter quality, transaction cost determines the extent to which economic agents resort to selfsufficiency rather than market exchange in order to satisfy their needs. Since self-sufficiency has been shown to constitute a bottom-line characteristic of TSOs, the theory of the division of labor captures the difference between the for-profit and third sectors as ultimately embodying exchange and selfsufficiency, respectively.

The self-sufficiency view of TSOs is wellsuitable to explaining rural TSOs since rural areas, compared to urban ones, exhibit characteristics increasing the cost of transacting, such as low population density, geoprahical dispersion, and poor infrastructure. Designated as rurality-specific, transaction cost stemming from these characteristics evidently constrains the ability of the for-profit sector, including market, hierarchy, and intermediate contracting, to satisfy human needs and thus creates a niche for TSOs as units of self-sufficiency. Further research is needed to operationalize this insight primarily by relating, both theoretically and empirically, specific determinants of rurality-specific transaction cost to specific institutional forms of TSOs in specific types of rural areas.

Finally, the proposed notion of TSOs' self-sufficiency entails some implications for the general economic theory of the third sector as well. Economists have long grappled with the problem of the separation between the demand-side and supplyside reasons for the existence of TSOs (Steinberg 2006, Hansmann 1987). Whereas the demand for this organizational form has been well explained in terms of market failures, the motives and objectives of those who create TSOs seem to have been merely assumed or postulated rather than explained. For example, in a recent authoritative review of the literature, Steinberg (2006) proposed a comprehensive classification of objectives of third sector entrepreneurs, yet his paper does not establish a causal connection between the origin of these objectives and the occurrence of market failures addressed by the respective TSOs. The notion of self-sufficiency, in contrast, does involve this connection, as self-sufficient productive activity is undertaken (supplied) by those who wish to directly consume (demand) its outputs. To be sure, the notion of self-sufficiency per se is not sufficient to fully integrate the demand-side and supply-side theoretical arguments for the third sector, since not all market failures give rise to entrepreneurial nonpecuniary objectives, as well as not all nonpecuniary objectives are best pursued through engagement in TSOs. Yet, this notion does make a certain contribution to the achievement of the sought-for theoretical integration. Exploring the full implications of this contribution appears to be a promising area of further research.

Acknowledgment. The author is grateful to two anonymous reviewers for helpful comments. The usual disclaimer applies.

\section{References}

Alchian, A. \& Demsetz, H. 1972. Production, information costs, and economic organization. American Economic Review 62: 772-795.

Baum, S., \& Weingarten, P. 2004. Typisierung ländlicher Räume in Mittel- und Osteuropa. Europa Regional 12: 149-158

Becker, G. \& Murphy, K. 1992. The division of labor, coordination costs, and knowledge. Quarterly Journal of Economics 107: 1137-1160.

Ben-Ner, A. 1986. Nonprofit organizations: why do they exist in market economies? In: Rose-Ackerman, S. (ed.). The Economics of Nonprofit Institutions: Studies in Structure and Policy. Oxford: Oxford University Press. p. 94-113.

Bonus, H. 1986. The cooperative association as a business enterprise: a study in the economics of transactions. Journal of Institutional and Theoretical Economics 142: 310-399.

Coase, R. 1937. The nature of the firm. Economica 4: 386-405.

Commission for Rural Communities 2006. Rural disadvantage: reviewing the evidence. London: Commission for Rural Communities. $241 \mathrm{p}$.

Demsetz, H. 1997. The economics of the business firm: seven critical commentaries. Cambridge: Cambridge University Press. $191 \mathrm{p}$.

Goodwin, M. 1998. The governance of rural areas: Some 
Vol. 18 (2009): 3-15.

emerging research issues and agendas. Journal of $R u$ ral Studies 14: 5-12.

Hansmann, H. 1987. Economic theories of nonprofit organization. In: Powell, W. (ed.). The Nonprofit Sector: A Research Handbook. New Haven et al.: Yale University Press. p. 27-42.

Hueth, B. \& Marcoul, P. 2003. An essay on cooperative bargaining in U.S. agricultural markets. Journal of Agricultural \& Food Industrial Organization 1: Article 10.

James, E. 1983. How nonprofits grow: a model. Journal of Policy Analysis and Management 2: 350-66.

James, E. \& Rose-Ackerman, S. 1986. Nonprofit enterprise in market economies. Harwood: Chur. 102 p.

Kendall, L., Knapp, M. \& Forder, J. 2006. Social care and the nonprofit sector in the Western developed world. In: Powell, W. and Steinberg, R. (eds). The Nonprofit Sector: A Research Handbook, $2^{\text {nd }}$ Ed. New Haven et al.: Yale University Press. p. 415-431.

Kydd, J. \& Dorward, A. 2004. Implications of market and coordination failures for rural development in least developed countries. Journal of International Development 16: 951-970.

Lakdawalla, D., \& Philipson, T. 2006. The nonprofit sector and industry performance. Journal of Public Economics 90: 1681-1698.

Mahoney, J. 1992. The choice of organizational form: vertical financial ownership vs. other methods of vertical integration. Strategic Management Journal 13: 559-584.

Menard, C. 2004. The economics of hybrid organizations. Journal of Institutional and Theoretical Economics 160: 1-32.

Minkoff, D., \& Powell, W. 2006. Nonprofit mission: constancy, responsiveness, or deflection? . In: Powell, W. and Steinberg, R. (eds). The Nonprofit Sector: A Research Handbook, $2^{\text {nd }}$ Ed. New Haven et al.: Yale University Press. p. 591-611.

OECD 2006. Das neue Paradigma für den ländlichen Raum: Politik und Governance (in German). Paris: OECD Publications. $184 \mathrm{p}$.

Ott, S. 2001. Introduction to the nonprofit sector. In: Ott, S. (ed.). The Nature of the Nonprofit Sector. Boulder, Westview Press. p. 179-189.

Peterson, C., Wysocki, A., \& Harsh, S. 2001. Strategic choice along the vertical coordination continuum. International Food and Agribusiness Management Review 4: 149-166.

Pindus, N. 2001. Implementing welfare reform in rural counties. Washington, D.C.: The Urban Institute. 23 p.

Poteete, A., \& Ostrom, E. 2008. Fifteen years of empirical research on collective action in natural resource management: struggling to build large- $\mathrm{N}$ databases based on qualitative research. World Development 36: 176-195.

Renting, H., Marsden, T. \& Banks, J. 2003. Understanding alternative food networks: exploring the role of short food supply chains in rural development. Environment and Planning A 35: 393-411.

Rose-Ackermann, S. 1996. Altruism, nonprofits, and economic theory. Journal of Economic Literature 34: 701728.
Salamon, L., Sokolowski, S. \& List, R. 2003. Global civil society: an overview. Baltimore, MD: The Johns Hopkins University Center for Civil Society Studies. 64 p.

Smith, A. 1981. An inquiry into the nature and causes of the wealth of nations, Vol. 1. Indianapolis: Liberty Fund. 543 p.

Staatz, J. 1987. Farmers' incentives to take collective action via cooperatives: a transaction cost approach. In: Royer, J. (ed.). Cooperative theory: new approaches. Agricultural Cooperative Service Report 18. Washington, DC: USDA. p. 87-107.

Steinberg, R. 2006. Economic theories of nonprofit organization. In: Powell, W. and Steinberg, R. (eds). The Nonprofit Sector: A Research Handbook, $2^{\text {nd }}$ Ed. New Haven et al.: Yale University Press. p. 117-139.

Terluin, I. 2001. Rural regions in the EU: exploring differences in economic development. Utrecht [u.a.]: Koninklijk Nederlands Aardrijkskundig Genootschap (in Dutch). $265 \mathrm{p}$.

Uphoff, N. 1993. Grassroots organizations and NGOs in rural development: opportunities with diminishing states and expanding markets, World Development 21: 607-622.

van der Ploeg, J., Renting, H., Brunori, G., Knickel, K. Mannion, J., Marsden, T., de Roest, K., Sevilla-Guzmán, E. \& Ventura, F. 2000. Rural Development: From Practices and Policies towards Theory. Sociologia Ruralis 40: 391-408.

Valentinov, V. 2008. The economics of nonprofit organization: in search of an integrative theory. Journal of Economic Issues 42: 745-761.

Weber, B., Duncan, G., \& Whitener, L. (eds) 2002. Dimensions of welfare reform. Kalamazoo, MI: W. E. Upjohn Institute of Employment Research. 490 p.

Weisbrod, B. 1988. The nonprofit economy. Cambridge, MA: Harvard University Press. 251 p.

Williamson, O. 1985. The economic institutions of capitalism: firms, markets, relational contracting. New York: Free Press. 450 p.

Williamson, O. 1991. Comparative economic organization: the analysis of discrete structural alternatives. Administrative Science Quarterly 36: 269-96.

Williamson, O. 1996. The mechanisms of governance. Oxford: Oxford University Press. $429 \mathrm{p}$.

Williamson, O. 2002. The theory of the firm as governance structure: from choice to contract. Journal of Economic Perspectives 16: 171-195.

Woolcock, N., \& Narayan, D. 2000. Social capital: Implications for development theory, research, and policy. World Bank Research Observer 15: 225-249.

Yang, X. \& Borland, J. 1991. A microeconomic mechanism for economic growth. Journal of Political Economy 99: 460-82.

Yates, H. 2002. Supporting rural voluntary action. London: National Council for Voluntary Organizations. 66 p.

Young, D. 1983. If not for profit, for what? Lexington, MA: Lexington Books. $171 \mathrm{p}$. 